\title{
Yellow nanosecond sum-frequency generating optical parametric oscillator using periodically poled LiNbO3
}

\author{
Jensen, Ole Bjarlin; Bruun-Larsen, M.; Balle-Petersen, O.; Skettrup, Torben
}

Published in:

Applied physics. B, Lasers and optics (Print)

Link to article, DOI:

10.1007/s00340-008-2949-y

Publication date:

2008

Link back to DTU Orbit

Citation $(A P A)$ :

Jensen, O. B., Bruun-Larsen, M., Balle-Petersen, O., \& Skettrup, T. (2008). Yellow nanosecond sum-frequency generating optical parametric oscillator using periodically poled LiNbO3. Applied physics. B, Lasers and optics (Print), 91(1), 61-63. https://doi.org/10.1007/s00340-008-2949-y

\section{General rights}

Copyright and moral rights for the publications made accessible in the public portal are retained by the authors and/or other copyright owners and it is a condition of accessing publications that users recognise and abide by the legal requirements associated with these rights.

- Users may download and print one copy of any publication from the public portal for the purpose of private study or research.

- You may not further distribute the material or use it for any profit-making activity or commercial gain

- You may freely distribute the URL identifying the publication in the public portal 


\title{
Yellow nanosecond sum-frequency generating optical parametric oscillator using periodically poled $\mathrm{LiNbO}_{3}$
}

\author{
Ole Bjarlin Jensen ${ }^{1 *}$, Morten Bruun-Larsen ${ }^{2}$, Olav Balle-Petersen ${ }^{3}$ and Torben Skettrup ${ }^{4}$ \\ ${ }^{1}$ DTU Fotonik, Technical University of Denmark, P.O. Box 49, Dk-4000 Roskilde, Denmark. \\ ${ }^{2}$ Danfysik A/S, Dk-4040 Jyllinge, Denmark \\ ${ }^{3}$ MedArt A/S, Dk-2650 Hvidovre, Denmark \\ ${ }^{4}$ Department of Physics, Technical University of Denmark, Dk-2800 Lyngby, Denmark \\ *Corresponding author: Fax +45 46774565, Telephone: +4546774553 \\ ole.bjarlin.jensen@risoe.dk
}

\begin{abstract}
Nanosecond yellow light has been generated through simultaneously phase matched sumfrequency generation and optical parametric oscillation in a periodically poled $\mathrm{LiNbO}_{3}$ crystal. $300 \mathrm{~mW}$ of yellow light at a wavelength of $586 \mathrm{~nm}$ has been generated from $1.3 \mathrm{~W}$ of laser power from a Q-switched Yb:YAG laser operating at $1031 \mathrm{~nm}$. The conversion efficiency of the device is $23 \%$.
\end{abstract}

PACS: 42.65.Ky Frequency conversion; 42.65.Yj Optical parametric oscillators 


\section{Introduction}

Lasers in the yellow spectral region have many applications within biomedicine due to the high absorption of hemoglobin. Currently the yellow lasers of choice for medical applications are copper vapour lasers at $578 \mathrm{~nm}$ and dye lasers operating at $585 \mathrm{~nm}$ and $595 \mathrm{~nm}$. These lasers are both bulky and inefficient and it would be attractive to develop a solid-state alternative to these lasers.

One path that has been followed for the generation of yellow light is second harmonic generation of a Raman shifted Nd:YAG laser [1]. In their approach $1.2 \mathrm{~W}$ of yellow light at $578 \mathrm{~nm}$ was generated at a repetition rate of $10 \mathrm{kHz}$. Another approach often used to reach the yellow spectral region is sum-frequency generation (SFG) of two neodymium lasers operating around $1064 \mathrm{~nm}$ and $1320 \mathrm{~nm}$ respectively [2-4]. Many Watts of yellow light have been generated in this way by using external cavity sum-frequency generation of two injection locked lasers [4]. Another potentially efficient method for the generation of yellow light is by employing sum-frequency generation to an optical parametric oscillator (OPO). Recently a nanosecond sum-frequency generating optical parametric oscillator was reported using a single KTA crystal to generate red light at $627 \mathrm{~nm}$ [5] and a continuous wave device operating at $629 \mathrm{~nm}$ has also been reported based on PPLN [6]. Multistep parametric processes have been known for many years and simultaneous sum-frequency generation in an optical parametric oscillator was first demonstrated by Andrews et al [7]. Recently Figen et al. [8] demonstrated the generation of red light by simultaneous phase matching of both the SFG and the OPO in a KTA crystal and Gao et al. [9] used periodically poled stoichiometric lithium tantalate to generate red-green-blue laser light. Second harmonic generation in an optical parametric oscillator was demonstrated by Ammann et al. [10]. A comprehensive overview of mulitstep parametric processes is given in [11]. 
In the present paper, we present a new method for generating light in the yellow spectral region. By using a diode-pumped Q-switched Yb:YAG laser as pump source for a periodically poled $\mathrm{LiNbO}_{3}$ (PPLN) optical parametric oscillator we generate a signal wave at $1358 \mathrm{~nm}$ and an idler wave at $4282 \mathrm{~nm}$. By sum-frequency generation of the pump laser and the signal wave we are able to generate yellow light at $586 \mathrm{~nm} .300 \mathrm{~mW}$ of yellow power was generated from $1.3 \mathrm{~W}$ of input pump laser power corresponding to a conversion efficiency of $23 \%$. Both the optical parametric oscillation and sum-frequency generation was phase matched in a single crystal containing two different poling periods. We furthermore present observations of secondary optical parametric oscillators pumped by the circulating signal wave and the generated yellow light.

\section{Experimental setup}

The experimental setup is shown in figure 1. It consists of a diode-pumped Q-switched Yb:YAG laser emitting up to $1.5 \mathrm{~W}$ of average power at a repetition rate of $6 \mathrm{kHz}$. The laser operates at a wavelength of $1031 \mathrm{~nm}$ with a spectral bandwidth of approximately $0.1 \mathrm{~nm}$ and emits a polarized output with a beam quality parameter $\mathrm{M}^{2}=1.2$. The maximum pulse energy is $250 \mu \mathrm{J}$ and the pulse duration is approximately 320 ns. The laser is directed through beam steering optics and a focusing lens with a focal length of $100 \mathrm{~mm}$ to achieve a beam waist of $65 \mu \mathrm{m}$ in the external optical parametric oscillator cavity. The cavity is arranged as a bow-tie ring cavity in order to obtain uni-directional operation and avoid back reflections to the pump laser. The cavity mirrors are two curved mirrors with $75 \mathrm{~mm}$ radius of curvature and two plane mirrors. The mirrors are

all coated for high reflectivity at the signal wavelengths from 1300-1400 nm and high transmission at the pump laser wavelength, the idler wavelengths (above $3000 \mathrm{~nm}$ ) and yellow 
wavelengths (550-600 nm). The two curved mirrors are separated by $115 \mathrm{~mm}$ and the remaining distance in the cavity is $173 \mathrm{~mm}$.

The PPLN crystal is $31.5 \mathrm{~mm}$ long, $8 \mathrm{~mm}$ wide and $0.5 \mathrm{~mm}$ thick and poled with two different poling periods. The poling period for the optical parametric oscillator (OPO) is $26.5 \mu \mathrm{m}$ and the poling length is $25 \mathrm{~mm}$. The remaining $6.5 \mathrm{~mm}$ of the crystal was poled with a period of $8.85 \mu \mathrm{m}$ to achieve phase matching of the sum frequency generation. The PPLN crystal was AR coated on both ends for the pump and signal wavelengths. The crystal was placed in an oven to control the temperature and avoid photorefractive damage. The optimum temperature for yellow light generation was found to be $193^{\circ} \mathrm{C}$. The PPLN crystal was placed in the cavity and oriented such that the pump laser traverses the SFG region of the crystal before the OPO region. In this way the SFG process takes advantage of the undepleted pump laser pulse and the conversion is more stable and efficient [12]. A filter is used to separate the yellow light from the pump, signal and idler waves.

The $1031 \mathrm{~nm}$ Yb:YAG laser was chosen as pump source because of the absorption of wavelengths above $4500 \mathrm{~nm}$ in $\mathrm{LiNbO}_{3}$. The idler wavelength generated by the OPO can be expressed in terms of the laser and sum frequency wavelengths as

$$
\lambda_{\text {idler }}=\left(\frac{2}{\lambda_{\text {laser }}}-\frac{1}{\lambda_{S F G}}\right)^{-1}
$$

Where $\lambda_{\text {laser }}, \lambda_{\text {idler }}$ and $\lambda_{S F G}$ are the laser, idler and sum frequency wavelengths respectively. If we had chosen to use a Nd:YAG laser at $1064 \mathrm{~nm}$ to generate light at $586 \mathrm{~nm}$, the signal wavelength would be $1304 \mathrm{~nm}$ and the idler wavelength would be $5773 \mathrm{~nm}$. This idler wavelength would experience strong absorption in the PPLN crystal and the OPO process would be less efficient. 
The idler wavelength is $4285 \mathrm{~nm}$ when using the Yb:YAG laser for the generation of $586 \mathrm{~nm}$ light. This idler wavelength only experiences a relatively low absorption in the PPLN crystal.

\section{Experimental results}

The OPO threshold was found to be $450 \mathrm{~mW}$ of average laser power corresponding to a pulse energy of $75 \mu \mathrm{J}$. Using tighter focusing in the PPLN crystal the OPO threshold could be lowered to $10 \mu \mathrm{J}$ but the extracted yellow power was considerably lower. The extracted yellow power as function of the input pump power is shown in figure 2. The maximum extracted yellow average power was $303 \mathrm{~mW}$ at an average pump power of $1300 \mathrm{~mW}$. This corresponds to a conversion efficiency of $23 \%$. It is seen that the conversion efficiency seems to saturate at approximately 23 \%. The signal wavelength is $1358 \mathrm{~nm}$ and the wavelength of the yellow light is $586 \mathrm{~nm}$ with a spectral bandwidth of approximately $0.1 \mathrm{~nm}$.

The OPO and SFG processes heavily deplete the laser pulses. A plot of the incoming laser pulse, the depleted laser pulse and the generated yellow pulse is shown in figure 3 . The pulse width of the generated yellow pulse is approximately 300 ns. The depletion of the laser pulse reaches 78 $\%$.

The beam quality parameter of the yellow light was measured to be $\mathrm{M}^{2}=1.28$ at maximum power, which corresponds well with the beam quality of the pump laser. The power variation of the yellow light was measured to be less than $1.5 \%$ during a 30 minutes measurement. We expect the power stability to increase with a more stable mechanical setup.

The SFG-OPO was also tested with the PPLN crystal turned so that the pump light first traverses the OPO region of the crystal. The maximum extracted yellow power was $75 \mathrm{~mW}$ in this 
configuration. The reduction in yellow power is caused by the heavy depletion of the pump beam during the pass through the OPO region of the crystal. The second harmonic of the signal wave was on the other hand enhanced in this way due to the high intracavity signal intensity and up to $150 \mathrm{~mW}$ of red light at $679 \mathrm{~nm}$ has been generated.

We have also tested the SFG-OPO using a $51.5 \mathrm{~mm}$ long PPLN crystal containing $44 \mathrm{~mm}$ with a period of $26.5 \mu \mathrm{m}$ and $7.5 \mathrm{~mm}$ with a period of $8.85 \mu \mathrm{m}$. The maximum extracted yellow power from this device was $235 \mathrm{~mW}$. It was found that the generated yellow power was limited by secondary OPOs pumped by the yellow light and the signal wave. The secondary OPO pumped by the yellow light in third order of the OPO period in the PPLN crystal generated a signal wavelength at $1046 \mathrm{~nm}$ and an idler wavelength of $1330 \mathrm{~nm}$, which could resonate in the cavity. The secondary OPO pumped by the signal wave at $1358 \mathrm{~nm}$ generated a secondary signal wavelength of $1834 \mathrm{~nm}$ and a secondary idler wavelength of $5232 \mathrm{~nm}$. Different parasitic processes in the PPLN generated light at many different wavelengths by up-conversion of the pump laser and the primary and secondary OPO waves. Simultaneously the device emitted light at $5232 \mathrm{~nm}, 4282 \mathrm{~nm}, 1834 \mathrm{~nm}, 1358 \mathrm{~nm}, 1330 \mathrm{~nm}, 1046 \mathrm{~nm}, 1031 \mathrm{~nm}, 917$ nm, 831 nm, 780 nm, 679 nm, 609 nm, 586 nm, 515 nm, 496 nm, 453 nm, 410 nm and 357 nm. No attempts were made to measure the power of the parasitically generated waves.

\section{Conclusion}

We have demonstrated a simple and efficient method of producing light in the yellow spectral range. By using sum-frequency generation inside the optical parametric oscillator cavity we have generated $300 \mathrm{~mW}$ of light at a wavelength of $586 \mathrm{~nm}$ with a conversion efficiency of $23 \%$. Other wavelengths can be generated by a different design of the PPLN crystal. We have furthermore observed secondary optical parametric oscillators pumped by the signal wave and 
the yellow light. These secondary optical parametric oscillators limit the amount of yellow power when using a long PPLN crystal.

\section{Acknowledgements}

The authors acknowledge the financial support by MedArt A/S and the Danish Academy of Technical Sciences.

\section{References}

1. H. M. Pask and J. A. Piper, Opt. Lett. 24, 1490-2, (1999).

2. J. Janousek, S. Johansson, P. Tidemand-Lichtenberg, S. Wang, J. L. Mortensen, P. Buchhave and F. Laurell, Opt. Exp. 13, 1188-1192 (2005).

3. Y. F. Chen, Y. S. Chen and S. W. Tsai, Appl. Phys. B. 79, 207-210 (2004).

4. J. C. Bienfang, C. A. Denman, B. W. Grime, P. D. Hillman, G. T. Moore and J. M. Telle, Opt. Lett. 28, 2219-2221 (2003).

5. Z. G. Figen and O. Aytür, Opt. Expr. 13, 4896-4902 (2005).

6. W. R. Bosenberg, J. I. Alexander, L. E. Myers, and R. W. Wallace, Opt. Lett. 23, 207-209 (1998).

7. R. A. Andrews, H. Rabin and C. L. Tang, Phys. Rev. Lett. 25, 605-608 (1970).

8. Z. G. Figen, A. Yalabik and O. Aytür, IEEE J. Quantum Electron. 42, 706-712 (2006).

9. Z. D. Gao, S. N. Zhu, S-Y. Tu and A. H. Kung, Appl. Phys. Lett. 89, 181101-1-3 (2006).

10. E. O. Ammann, J. M Yarborough and J. Falk, J. Appl. Phys. 42, 5618-5634 (1971).

11. S. M. Saltiel, A.A. Sukhorukov and Y. S. Kivshar, Progress in optics 47, 1-73 (2005). 
12. G. T. Moore and K. Koch, IEEE J. Quantum Electron. 29, 961 (1993). 


\section{FIGURE CAPTIONS}

Fig. 1. Experimental setup for yellow light generation. The Q-switched Yb:YAG laser is mode matched to the ring cavity and the PPLN crystal contains periods for optical parametric oscillation and sum-frequency generation.

Fig. 2. The extracted yellow power (triangles) and conversion efficiency (squares) as function of the pump laser power.

Fig. 3. Plots of the incoming laser pulse, the depleted laser pulse and the generated yellow pulse from the SFG-OPO. 


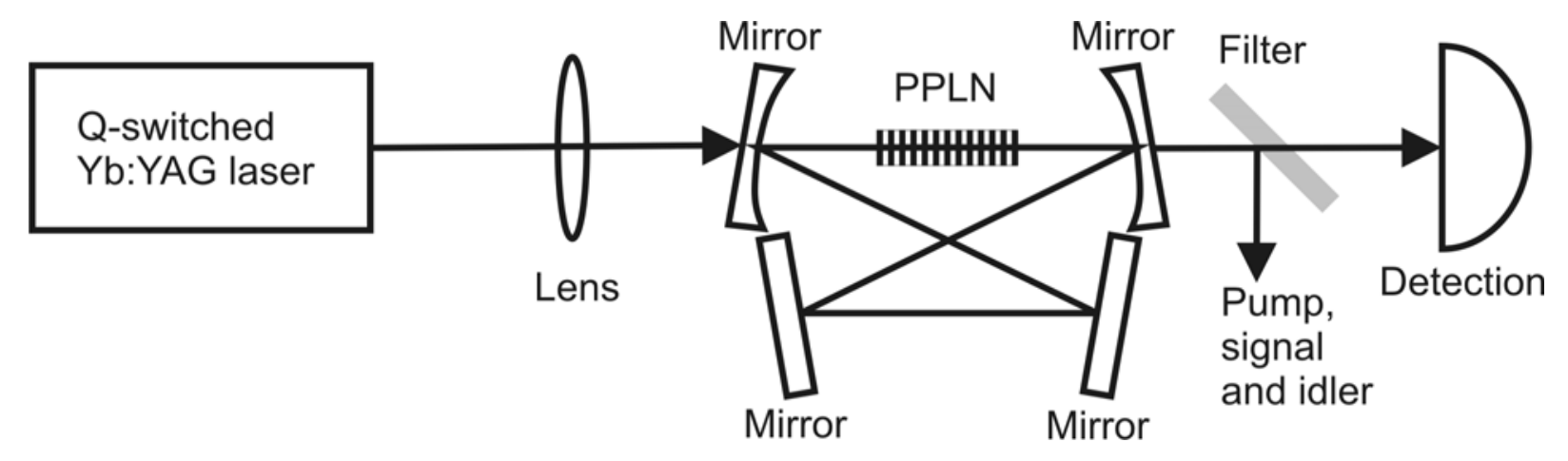

Fig. 1. Experimental setup for yellow light generation. The Q-switched Yb:YAG laser is mode matched to the ring cavity and the PPLN crystal contains periods for optical parametric oscillation and sum-frequency generation. 


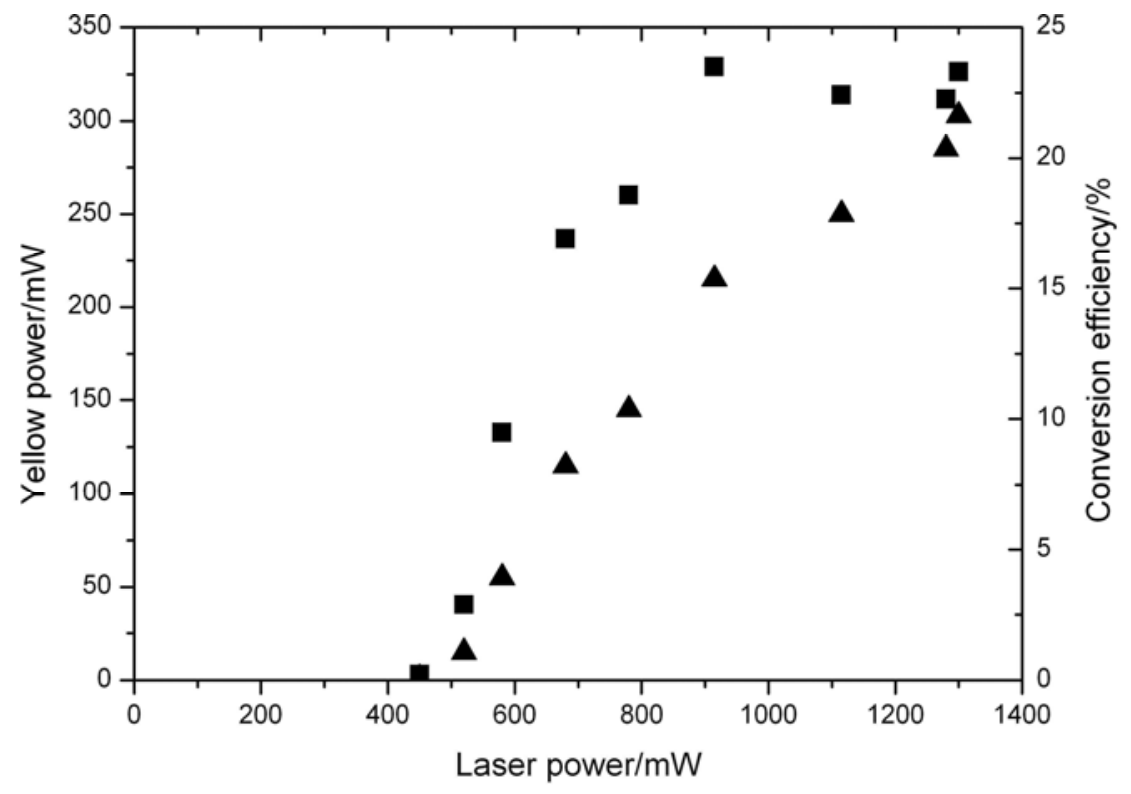

Fig. 2. The extracted yellow power (triangles) and conversion efficiency (squares) as function of the pump laser power. 


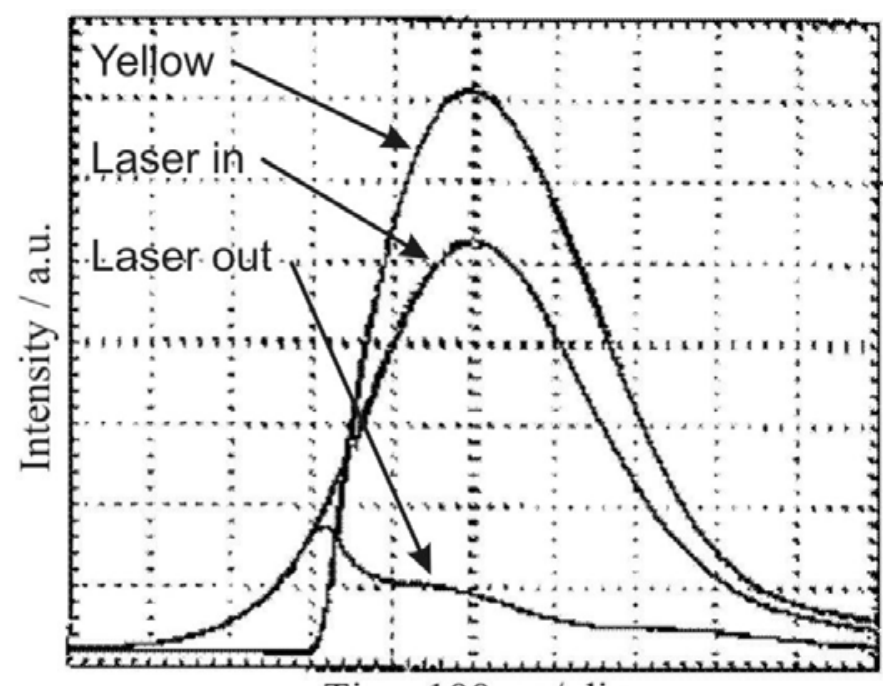

Time 100 ns / div

Fig. 3. Plots of the incoming laser pulse, the depleted laser pulse and the generated yellow pulse from the SFG-OPO. 